\title{
Ingeniería Del Conocimiento Aplicada Al Estudio De Percepción Del Turismo Utilizando Ontologías OWL Derivadas De Un Léxico Extendido Del Conocimiento Del Dominio
}

\author{
Dr. Manuel Ramón González Herrera \\ Ing. Yanet Garay Santos \\ Dr. Julián Alberto Álvarez Hernández. \\ Universidad Autónoma de Ciudad Juárez. México
}

doi: 10.19044/esj.2016.v12n26p307 URL:http://dx.doi.org/10.19044/esj.2016.v12n26p307

\begin{abstract}
The integration of Knowledge Engineering and Tourism strengthens the interdisciplinary studies as an area of scientific research. Therefore, the aim of this study is to compare the perceptions of different focus groups regarding the sustainability of tourism development in Ciudad Juarez, through conceptual modeling, specifically, using ontologies OWL derived from the Knowledge of the Domain in an Extended Lexicon. As results, theoretical approaches of tourism as a scientific discipline are systematized and interdisciplinary related to Knowledge Engineering. The tourism system of Ciudad Juarez is characterized, recognizing that it should be reoriented towards the formation of a Smart Tourist Destination, as an advanced concept in tourism. Finally, the knowledge apprehended by each focus group in relation to the tourism model is analyzed, in order to obtain a comparison between the four ontologies generated, and this concludes with the integration of perceptions in an OWL synthesis, which would guide the strategic projection of the destination.
\end{abstract}

Keywords: engineering, knowledge, smart tourism, interdisciplinary, ontology, sustainable

\section{Resumen}

La integración de la Ingeniería del Conocimiento y el Turismo potencia la interdisciplinariedad como área de investigación científica. Por tanto, es objetivo del estudio comparar las percepciones de diferentes grupos focales respecto a la sustentabilidad del desarrollo turístico de Ciudad Juárez mediante la modelación conceptual, utilizando específicamente Ontologías 
OWL derivadas de un Léxico Extendido del Conocimiento del Dominio. Como resultados, se sistematizan enfoques teóricos del turismo como disciplina científica y se relacionan de forma interdisciplinar con la Ingeniería del Conocimiento. Seguidamente, se caracteriza el sistema de turismo de Ciudad Juárez reconociendo que debería reorientarse hacia la conformación de un Destino Turístico Inteligente como concepto avanzado en el turismo. Finalmente, se analiza el conocimiento aprehendido por cada grupo focal con respecto al modelo turístico, con el fin de obtener un escenario comparado entre las 4 Ontologías generadas, y concluir con la integración de las percepciones en una Ontología OWL síntesis, la cual permitiría orientar la proyección estratégica del destino.

Palabras clave: ingeniería, conocimiento, turismo inteligente, interdisciplinariedad, ontología, sustentable

\section{Introducción}

El concepto de Ingeniería del Conocimiento no debe ser considerado como un constructo ajeno a la gestión del conocimiento turístico sustentable; la sustentabilidad turística está avanzando a la par de la tecnología, la innovación y la competitividad; lo cual está estrechamente asociado a las principales tendencias identificadas para esta área del conocimiento (Cabrini, 2014), y a los avances de la investigación basada en los enfoques interdisciplinares. Ante este supuesto cabe preguntarse ¿cómo puede ser sustentable el turismo sin una sólida base de conocimientos científicos que sirva de soporte al entendimiento y la actuación de los actores del destino turístico? La incompatibilidad del turismo con las funciones económicas y sociales del espacio en que tiene lugar, es en gran medida un efecto directo o indirecto de la falta de información confiable y de conocimientos científicos que permitan garantizar prácticas más eficientes.

La integración de los fundamentos de la Ingeniería del Conocimiento y el turismo como objeto de estudio, pone de relieve la interdisciplinariedad como área de conocimiento, la cual va más allá de una sola disciplina científica en busca de lo conexo y de las posibles relaciones que caracterizan la realidad objetiva. Los estudios del turismo requieren metodológicamente el sustento colaborativo de otras especialidades para una mejor práctica científica, sin perder su esencia como disciplina académica. En este particular, el examen y aplicación de métodos, herramientas, y técnicas de la ingeniería permiten una visión multidimensional del fenómeno turístico. Esto ha caracterizado en décadas recientes a otras disciplinas académicas y ciencias particulares, dando lugar a estudios de biotecnología, electroquímica, termodinámica, entre otros, lo cual hace suponer que esta dinámica pudiera caracterizar el futuro desarrollo de las ciencias. 
En opinión de E. Morín (2010), la disciplina es una categoría organizacional en el seno del conocimiento científico; pero la institución disciplinaria entraña riesgos de hiperespecialización y cosificación del objeto de estudio, indicando que la apertura es necesaria, a la vez que justifica como ciertas concepciones científicas mantienen su vitalidad al oponerse al encierro disciplinario (Morín, 2010). Ya es común encontrar dentro de diversas escuelas de estudios turísticos la formación de Ingenieros en Gestión Turística; especialidad que conjuga diferentes áreas del conocimiento aplicando técnicas de gestión, planificación, evaluación y comercialización de proyectos, productos y servicios turísticos con enfoque sustentable (Instituto Profesional de Chile, 2016). Este enfoque potencia la preparación profesional en un ámbito tecnológico, de innovación, creatividad e inteligencia profesional mucho más integrador.

La presente investigación aborda como objeto de estudio la Ingeniería del Conocimiento y el Turismo Sustentable e Inteligente como disciplina científica, con el propósito de aprovechar las oportunidades que tributan a la gestión del conocimiento. Tales oportunidades se relacionan mediante la modelación del conocimiento aportado por grupos de discusión y sus interpretaciones - comparaciones. Este enfoque está favorecido por la innovación, la sustentabilidad, y la implementación de tecnologías de la información como alternativas para promocionar, acceder y dinamizar la gestión de la información y del conocimiento turístico. Dicho proceso se inscribe en el contexto de los Destinos Turísticos Inteligentes como espacios innovadores que hacen uso avanzado de las TICs, en forma tal que se genera un sistema de inteligencia para capturar la información de forma rápida, así como analizar y comprender los acontecimientos en tiempo real.

Es objetivo general de esta comunicación comparar los resultados de las percepciones de diferentes grupos focales con respecto al modelo de desarrollo del turismo en Ciudad Juárez mediante la modelación conceptual, utilizando Ontologías OWL derivadas de un Léxico Extendido del Conocimiento del Dominio, con el fin de conformar una base de opiniones ciudadanas que sirva de soporte al Programa de Reactivación del Turismo. Los objetivos específicos que orientaron la investigación son:

1. Sistematizar y estudiar experiencias relativas al análisis del turismo como disciplina científica y la contribución de la ingeniería del conocimiento y del turismo inteligente.

2. Planificar, desarrollar y sistematizar las percepciones -conocimientossobre el modelo de desarrollo turístico de Ciudad Juárez mediante la utilización de la técnica de grupos focales y la aplicación de un Procedimiento de Evaluación Rápida (PER).

3. Generar y visualizar Ontologías OWL semi - automáticas según el léxico capturado para cada grupo focal con el propósito de comprender y 
modelar las perspectivas de los diversos actores con respecto al desarrollo del turismo en Ciudad Juárez.

Como resultados se realiza una sistematización de las bases teóricas del turismo como disciplina científica y se relaciona a través del principio de la interdisciplinariedad con la Ingeniería del Conocimiento. Seguidamente se caracteriza Ciudad Juárez como escenario que pudiera introducir en su gestión los aportes del conocimiento científico asociado al turismo como disciplina científica, la ingeniería del conocimiento y el turismo inteligente. Finalmente, se presenta una sistematización del conocimiento aprehendido por cada uno de los grupos focales respecto al modelo de desarrollo turístico de Ciudad Juárez, con el fin de obtener un escenario comparado entre las 4 Ontologías OWL y concluir con la integración de todas las percepciones en una Ontología OWL síntesis, la cual permitiría orientar el trabajo de proyección estratégica del destino.

\section{Revisión de la literatura. \\ El turismo como disciplina científica.}

Desde hace varias décadas se ha debatido “... respecto al status de ciencia, cientificidad y de lo disciplinario del turismo, que ha empantanado el avance de la producción de su conocimiento, el cual tiene que ver concretamente con la cuestión epistemológica del turismo" (Castillo, 2011:517). Entre sus argumentos indica que la "aparición de comunidades científicas en el turismo se puede datar desde 1941 cuando W. Hunzinker y K. Krapf crearon la Asociación Internacional de Expertos Científicos en Turismo" (Ibídem). Añade que "la discusión del turismo si es ciencia o disciplina... tiene que ver con el concepto de ciencia del cual se parte para evaluar la producción de su conocimiento. Los paradigmas del conocimiento del turismo en realidad se limitan a unos cuantos enfoques disciplinarios que profundizan en ciertas teorías, modelos y conceptos generales, dando lugar a la incredulidad...de que el turismo pueda desarrollarse como una disciplina" (Castillo, 2011:535).

El análisis de la información científica, y del conocimiento turístico, está marcado por muy disimiles vacíos de información (gaps), problemas conceptuales, y temas contradictorios objeto de análisis y enfoques de investigación, los que han sido motivo de estudio cada vez con mayor relevancia desde las últimas décadas del siglo $\mathrm{XX}$. De acuerdo con la opinión de Abril (1997) [aborda la teoría de la información en el contexto de la teoría de la comunicación-cultura masiva], en los manuales sobre problemas de la información predominan los enfoques psicosociológicos y el énfasis en la teoría de la noticia, y en los llamados efectos de los medios; al tiempo que destaca una perspectiva metodológica interdisciplinar en la que los enfoques culturológicos y sociosemióticos alcanzan bastante relieve (Abril, 1997). 
Según opiniones epistemológicas de K. Popper-uno de los principales filósofos de la ciencia del siglo XX- tanto la evolución como el desarrollo del conocimiento exigen una estructura innata genéticamente a priori -aunque no válida a priori-, que suministra el material de partida que la selección natural o la crítica racional han de modificar para producir el siguiente estadio de desarrollo (Popper, et al., 2008). El autor en "La lógica de la investigación científica", toma como punto de partida de su epistemología el realismo del sentido común, realismo crítico por cuanto afirma constantemente y en contra del mito del marco teórico, la necesidad de poner en tela de juicio el propio punto de partida (Ibídem), enfoque bien debatido en la literatura científica y en el campo específico de la metodología de la investigación turística.

En particular, el turismo como disciplina científica actual ha devenido de la información y el conocimiento producido durante la denominada Nueva Era del Turismo (1945- actualidad), etapa de desarrollo caracterizada por un crecimiento impetuoso del turismo (dinámico); fuerte expansión de los flujos turísticos internacionales (expansivo); y un vuelco del turismo exclusivo al turismo de masas ("masivo"). Importante rol han desempeñado los acontecimientos económicos, políticos, tecnológicos, ambientales y sociales que han tenido lugar durante la nombrada "I Revolución del turismo" de tipo desarrollado o masivo que comenzó aproximadamente en la segunda mitad del siglo XX y la "II Revolución del turismo" donde el protagonismo corresponde al ocio (En González, 2010).

En la consideración de Guevara et al., (2006), desde una mirada institucional, el turismo ha constituido una actividad económica y una práctica social. Refiere que el proceso histórico por el que ha pasado y su devenir merecen un cuidadoso seguimiento a través de la generación de estudios surgidos desde diferentes disciplinas sociales que contribuyen a la construcción del conocimiento de "lo turístico" (Guevara, 2006:13). Esta es una problemática característica del proceso de consolidación de las bases del conocimiento científico turístico, ya que la información y construcción del conocimiento ha sido más exógena que endógena y ha estado pobremente auto-gestionada desde este propio campo disciplinar, debido a múltiples factores objetivos y subjetivos que no han de ser objeto de análisis aquí, aunque si bien invitan a la reflexión.

Por tal razón, en opinión de diversos investigadores y académicos, el turismo es un fenómeno "mal conocido y peor teorizado", enunciado que hizo valer J. Aramberri desde finales del siglo anterior (Aramberri, 1988), y ha sido tomado como referente en diversos artículos y otras publicaciones sobre el estado del conocimiento y la investigación en turismo. Es necesario continuar fundamentando las bases conceptuales del sistema de turismo como disciplina científica en correspondencia con las perspectivas actuales de la Teoría Turística Moderna, y transitar desde la implementación del enfoque analítico 
reduccionista hacia el totalizador $\mathrm{u}$ holístico, incorporando la conceptualización de la teoría de sistemas (sistema de turismo) y de los procesos (procesos turísticos) a los estudios sobre el conocimiento turístico; este último frecuentemente relacionado en la literatura como "reingeniería turística” (Velázquez, 2013), enfocada con una visión innovadora.

Cabe preguntarse ¿Por qué es necesaria la conformación de una sólida Teoría Turística? Entre las primeras aproximaciones pudieran plantearse la necesidad de sustentar una concepción filosófica del turismo sobre la base del paradigma científico con que se compromete nuestra actuación; asumir un posicionamiento conceptual y procedimental científico que permita identificar y proyectar los problemas del turismo a resolver; enfocar la gestión práctica del turismo como actividad socioeconómica de carácter complejo, holístico, sistémico, dinámico, espacio-temporal, humano y socializador; garantizar un mejor desempeño profesional en el turismo; y examinar la naturaleza y el estado actual del conocimiento turístico como fundamento para la construcción de nuevos saberes, convirtiendo de esta forma el conocimiento científico en un nuevo "valor" para el turismo.

A propósito, sostienen R. Guevara, S. Molina y J. Tresserras que la "conformación del conocimiento sobre lo turístico en México, con todas las alternativas, temáticas y concepciones que este término pueda suponer $\mathrm{y}$ comprender, ha sido posible por las aportaciones generadas principalmente desde el área pública y la académica... en los dos ámbitos se reconoce que existe un desfase permanente entre el desarrollo de la actividad y el de la propia investigación; en este desfase, la primera siempre ha ido aparentemente más rápida que la segunda. Lo que ocurre en este sentido es grave, dado que la experiencia social muestra, en torno a la relación teoría y práctica, que en la medida en que la investigación oriente, sea soporte o acompañe el desarrollo de las múltiples actividades económicas, estas últimas tendrán un sentido y una dirección más estratégica e integral en términos de crecimiento (Guevara, 2006:17).

Como parte del análisis de las técnicas de gestión y representación del conocimiento, Sandoval (2015) citando a Martínez (2001), reconoce que para poder comprender el proceso de Gestión del Conocimiento se debe diferenciar desde su estructura, la cual está compuesta por datos, información, y conocimiento (Sandoval, 2015). Precisa refiriendo a Martínez (2001) que el conocimiento es el resultado conclusivo de analizar la información y constituye la unión de la información, el contexto y la experiencia adquirida. Indica la existencia de diversas formas de administrar, interpretar y representar el conocimiento, dependiendo de la necesidad o forma en que se tratará la información; a la vez que tipifica las diferencias entre el conocimiento explícito, conocimiento tácito aprendido por experiencia, conocimiento declarativo, conocimiento procedural, conocimiento de causas, conocimiento 
condicional, conocimiento relacional y conocimiento pragmático (Ibídem), todo lo cual es fundamental para la comprensión de un dominio del conocimiento.

Debaten Guevara et al., (2006) -a propósito de la generación del conocimiento científico en turismo- sobre diversas fuentes de producción, las cuales relacionan con instancias públicas, instituciones académicas y de investigación científica, e instancias privadas, cada una con sus particularidades (Guevara, 2006). En función de ello, es preciso recalcar el importante aporte de turistas y comunidades anfitrionas al conocimiento del turismo, ya que son quienes conocen el fenómeno turístico de manera vivencial. Es de suma importancia integrar a turistas y visitantes al proceso de producción del conocimiento turístico; conocer su base de opiniones, y sus visiones sobre oportunidades de mejora, haciéndolos partícipes voluntarios de la contribución a un mejor entendimiento y a una efectiva práctica del turismo sustentable. Este argumento social justifica el trabajo con grupos y líderes de opinión, con visitantes del destino y con la comunidad anfitriona en general.

\section{Ingeniería del conocimiento y Turismo Inteligente.}

En la actualidad la Ingeniería del Conocimiento ha adquirido gran importancia científica, y es considerada específicamente como una actividad de modelado, lo cual es de alto valor utilitario para los estudios turísticos. Un modelo es una abstracción para fines de entendimiento de cierta parte de la realidad; en tal sentido, la Ingeniería del Conocimiento se encarga de extraer, modelar, analizar y codificar el conocimiento de un experto en determinada área (Schreiber, 2000), en este caso particular del saber turístico.

A los fines de la investigación se asume que la Ingeniería del Conocimiento (IC) "es la disciplina tecnológica que se centra en la aplicación de una aproximación sistemática, disciplinada y cuantificable al desarrollo, funcionamiento y mantenimiento de Sistemas Basados en Conocimiento. En otras palabras, el objetivo básico de la IC es el establecimiento de metodologías que permitan abordar el desarrollo de sistemas basados en conocimientos de una forma más sistemática" (Palma, et al., 2000:47). Las mismas pueden ser de gran utilidad para la comprensión de las plataformas conceptuales inherentes al conocimiento turístico.

En particular, la modelación conceptual utilizando la generación semiautomática de una Ontología OWL derivada de un Léxico Extendido del Conocimiento del Dominio (KDEL) es el constructo básico en que se sustenta el presente estudio. De tal forma, el conocimiento del dominio permite especificar "los hechos y asunciones que necesita el proceso de razonamiento para llevar a cabo su cometido en el dominio de aplicación.

El conocimiento del dominio puede ser estructurado en una serie de modelos del dominio, los que proporcionan una visión coherente de las 
distintas partes del dominio de aplicación. Por consiguiente, es necesario especificar la forma, estructura y contenido del conocimiento relevante para la aplicación. La forma y la estructura constituyen lo que se denomina la ontología del dominio" (Palma, et al., 2000:62).Cabe destacar que en los Dominios de Estructura Informal (Olmos, et al., 2014) -Informal Structure Domains, ISD por sus siglas en inglés- la información es poco estructurada, informal y depende del contexto para su interpretación. Los conceptos y sus relaciones son generalmente definidos por expertos del dominio con el fin de lograr una mejor comprensión del mismo. En el ámbito de esta investigación el dominio del turismo es considerado un Dominio de Estructural Informal. En tal sentido, es de gran importancia el trabajo colaborativo entre el Ingeniero en Sistemas y el experto en turismo para garantizar una óptima comprensión de la problemática objeto de estudio.

En ocasiones se requieren herramientas especializadas que ayuden a entender el dominio de aplicación; estas herramientas son conocidas como modelos conceptuales (Hossian, 2012). Para el ámbito de esta investigación se define una ontología como una especificación formal y explícita de cómo representar las entidades que existen en un dominio de interés determinado y las relaciones que existen entre estas entidades (Gruber, 1993; Lock \& Sommerville, 2005; Sidhu, \& Chang, 2006). Uno de los desarrollos más recientes en lenguajes de ontologías es OWL (Oberg, et al., 1998). Una Ontología OWL se puede definir mediante la sintaxis RDF / XML. Los principales componentes de una Ontología OWL son las clases, los individuos y las propiedades.

Para la gestión del conocimiento turístico se asume que el lenguaje generalmente utilizado es ambiguo y depende del contexto para su interpretación, así como de las diferentes áreas del conocimiento de que se ha venido nutriendo y de los especialistas que hacen uso del mismo. El LEL Léxico Extendido del Lenguaje/Language Extended Lexicon- es un léxico que permite representar y documentar, con tecnología de hipertexto un conjunto de símbolos que representan el lenguaje del dominio en estudio. El principal objetivo de LEL es conocer y familiarizarse con el vocabulario del experto del dominio (Loucopoulos, et al., 1992; Sampaio, 1993), en este caso de la problemática turística abordada. Para generar el LEL se registran símbolos (palabras o frases) peculiares o relevantes del dominio turístico.

En consecuencia, el proceso de construcción del LEL tiene como propósito principal el conocimiento relativo al vocabulario del objeto de estudio. Según E. Sandoval el LEL se obtiene del Universo del Discurso (UdeD), y regularmente se integra en seis actividades, algunas de las cuales pueden ocurrir simultáneamente: 1) identificación de fuentes de información; 2) identificación de símbolos; 3) clasificación de símbolos; 4) descripción de símbolos; 5) verificación del LEL; y 6) validación del LEL (Sandoval, 2015). 
De tal forma, el uso de léxicos es altamente recomendado para obtener una mejor comprensión de dominios (Gil, 2002), en función de lo cual se desarrollan nuevos enfoques con el propósito de detectar información oculta en el discurso del experto a través de la generación de ontologías y la realización de bitácoras de creencias. El KDEL -Knowledge Domain Extended Lexicon / Léxico Extendido del Conocimiento del Dominio- es una herramienta de software, previamente desarrollada en el ámbito de esta investigación, que permite construir un léxico (similar al léxico que puede ser construido en LEL) para describir ISD -Dominios de Estructura Informal / Informal Structure Domains- (Garay, 2013). Después de construir el léxico del dominio utilizando KDEL, se realiza un proceso de conversión del léxico a Ontología OWL. La Ontología OWL obtenida es considerada una ontología base, ya que contiene los términos y las relaciones del dominio turístico que se analiza. La persona que utilice la ontología puede adicionar nuevos términos y relaciones o modificar las ya existentes.

La ontología puede además ser visualizada y modificada en Protégé (http://protege.stanford.edu/), el cual es un editor gráfico para Ontologías OWL. Para generar la visualización de la ontología se eligió la estructura de una red semántica, ya que representa perfectamente el grafo construido con los nodos y relaciones de la ontología (Ibídem). Los nodos de la red semántica representan los conceptos de la Ontología OWL y los arcos que unen los nodos representan las relaciones, que son las propiedades de objetos de OWL. Los arcos son dirigidos en la dirección de nodo apuntador -> conector -> nodo apuntado. Como parte de la visualización desarrollada en el ámbito de esta investigación, se llevó a cabo un diseño y desarrollo de la parte interactiva de la visualización de la ontología. Para esto se utilizaron las funcionalidades de D3, que permiten dar movimiento al gráfico o detenerlo, aumentar o disminuir el espacio entre nodos, y mediante el uso de Jquery y Ajax se manipula la información de los nodos y se hace editable (Ibídem).

Asociado a esta área del conocimiento ROTACODE (2014) afirma que "el turismo inteligente es un concepto avanzado en el turismo, desarrollado por una industria turística más responsable y conectada, y por personas que han transformado sus hábitos a la hora de viajar, y que ya no son meros turistas, si no turistas inteligentes del S.XXI conectados a las redes sociales, disfrutan de la sociedad del ocio de una forma activa porque interactúan con el entorno de forma inmediata y donde lo importante es la calidad de la experiencia que se vive" (ROTACODE, 2014). Refiere que el turismo inteligente está centrado en la innovación y la sustentabilidad; destaca que usar tecnologías de la información es lo más apropiado para promocionar, acceder y dinamizar el sector, siempre en contacto con las redes sociales (Ibídem).

De acuerdo con la Sociedad Estatal para la Gestión de la Innovación y las Tecnologías Turísticas (SEGITUR), la tecnología ha sido un incremento 
innovador y de vanguardia altamente exagerado que ha cambiado la manera del quehacer en la práctica del turismo. Como el internet ha cambiado la forma de realizar las actividades cotidianas, tanto en lo personal como en el profesional y laboral (SEGITUR, 2015). Esta tendencia debe tener una respuesta inmediata en lo relativo a la gestión del conocimiento turístico que le sirve de base.

Afirma S. Castro que asociado a este concepto se desarrolló desde 2013 en España el de Destinos Turísticos Inteligentes (DTI) (Castro, 2016). El DTI es un "espacio turístico innovador basado en una infraestructura tecnológica de vanguardia que responde al desarrollo sostenible del territorio turístico, facilita la interacción e integración del visitante con su entorno e incrementa la calidad de la experiencia en el destino, a la vez que mejora la calidad de vida de sus residentes" por lo "que conciben el territorio como una plataforma tecnológica, en los que la clave es el enlace inmediato a una información geo-localizada y de proximidad (ROTACODE, 2014).

Coincide SEGITUR que un DTI está caracterizado por atributos tales como el carácter innovador, infraestructura tecnológica, desarrollo sostenible, accesibilidad para todos, interacción e integración del visitante con el entorno, y calidad de la experiencia en el destino (SEGITUR, s/a: 4). Resaltan López y García (2015) que un DTI es un territorio comprometido con factores ambientales, culturales y socioeconómicos, dotado por un sistema de inteligencia que capte la información de forma rápida, analice y comprenda los acontecimientos en tiempo real, con el fin de facilitar la interacción del visitante" (López, et al., 2015).

Se infiere que debido a ello, las organizaciones y destinos turísticos se ven impulsados a enfocarse en el posicionamiento electrónico por medio de buscadores, distribuidores electrónicos, redes sociales, la web 2.0 y 3.0. En el turismo actual es frecuente presenciar en los espacios más turísticos a los visitantes con Smartphone o Tablet en mano, fotografiando, grabando video y compartiendo mediante las redes sociales, así como visitando páginas web para tomar decisiones relativas al ciclo de vida del viaje. El desarrollo de nuevos dispositivos, como las redes sociales, y la información que transita a través de sistemas inteligentes ha generado un conocimiento de gran impacto que ha ido en crecimiento en todos los sectores de la actividad turística (Castro, 2016).

\section{Metodología implementada en la investigación.}

La investigación se sustenta en el enfoque interdisciplinar de la Ingeniería del Conocimiento en el dominio del Turismo Sustentable. El dimensionamiento metodológico se apoyó en la modelación conceptual y comparación de las percepciones correspondientes a grupos focales que se integraron al estudio mediante un Proceso de Evaluación Rápida (PER). Se 
generaron Ontologías OWL derivadas de un Léxico Extendido del Conocimiento del Dominio (KDEL). El desarrollo de los grupos focales sirvió de marco textual para la elaboración del KDEL, y el posterior análisis del discurso de los participantes con respecto a su conocimiento turístico sobre el destino.

Según los enfoques cualitativos de la investigación para la organización e integración de los grupos focales se conformaron cuatro unidades de estudio: Grupo 1 Empresarios y Trabajadores de Turismo (22 participantes); Grupo 2 Hoteleros (12 participantes); Grupo 3 Tomadores de Decisiones (15 participantes); y Grupo 4 Comunidad en General (10 participantes).

Las preguntas presentadas a debate fueron las siguientes:

1. ¿Cuál es la vocación e importancia del turismo para la ciudad?

2. ¿Qué factores han incidido negativamente hasta el presente en la ciudad para: hacer del turismo una de las prioridades municipales; tener turistas/ visitantes totalmente satisfechos; mantener atractivos turísticos sustentables; y contar con empresas turísticas competitivas?

3. ¿Qué debemos hacer para consolidarnos como un destino turístico de experiencias y excelencia a mediano y largo plazo? Se tomó en consideración: factibilidad de un plan estratégico de incentivos para la reactivación del turismo en Juárez; creación de corredores turísticos y definición de la vocación de cada uno de ellos; cambios en la imagen y percepción turística de Juárez; creación de una cultura en la comunidad como anfitriona del turismo.

El experto del dominio turístico analizó los resultados obtenidos e interpretó los modelos conceptuales con el fin de entender las perspectivas y necesidades de los diferentes grupos participantes con respecto al modelo del turismo en Ciudad Juárez. Para hacer el análisis de los resultados el experto utilizó KDEL para construir un léxico y luego semiautomáticamente se construyó y visualizó cada una de las Ontologías OWL. Mediante el trabajo colaborativo Ingeniero en Sistemas - Experto en Turismo se validaron los términos y las relaciones encontradas.

La investigación que sirvió de base al presente estudio "Generación semi-automática de una ontología OWL derivada de un Léxico Extendido del Conocimiento del Dominio (KDEL)", Y. Garay (2013), propone un nuevo enfoque para el proceso de entendimiento y modelado de un ISD, usando un Léxico Extendido del Conocimiento del Dominio a partir del cual se genera y visualiza cada Ontología OWL, esto con el fin de mejorar el entendimiento y modelado de los ISD. Como corroboración de la factibilidad de su propuesta la autora demuestra a través de diferentes casos de estudio la representación visual de los ISD, a través de la generación y visualización de Ontologías OWL y el análisis de los resultados (Garay, 2013). 
Consecuente con esta propuesta en el presente estudio se realiza la generación de ontologías de manera semi-automática, las que permitieron modelar el dominio objeto de estudio a partir del léxico turístico previamente construido. Se trata de la propuesta de ontologías no sólo con objetos y sujetos detectados en el discurso de los participantes; si no que, incorpora además verbos, y definiciones, lo cual enriqueció favorablemente el proceso de comprensión de la información recopilada a través de los grupos focales.

Las tareas básicas desarrolladas como parte del proceso investigativo fueron:

1. Delimitación del dominio a modelar para la comprensión de la percepción de los impactos del turismo sobre las comunidades anfitrionas.

2. Elaboración del Léxico Extendido del Conocimiento del Dominio a partir de las relatorías y transcripción de las grabaciones de los debates realizados en cada grupo focal.

3. Modelación conceptual y análisis semántico de las percepciones correspondientes a cada grupo focal a través de Ontologías OWL derivadas de un Léxico Extendido del Conocimiento del Dominio.

4. Interpretación comparada entre las ontologías correspondientes a cada grupo focal y síntesis de la información en un solo modelo final.

\section{Discusión y resultados.}

\section{El contexto de Ciudad Juárez. Bases para la gestión del turismo inteligente}

Ciudad Juárez y El Paso, Texas, conforman un espacio urbano binacional en la frontera central entre México - Estados Unidos, definiendo en el mapa de América del Norte uno de los conglomerados más importantes, complejos, heterogéneos, y polémicos del norte de México; lo cual está condicionado por factores históricos, políticos, tecnológicos, económicos, demográficos, sociales y ambientales. En Ciudad Juárez, el sector industrial es significativamente más desarrollado que otras actividades económicas, pero su ubicación privilegiada, accesibilidad y conectividad favorecen un turismo de frontera dinámico, con el cual pueden ser asociados diferentes atractivos de sitio, actividades y eventos de interés para diversos mercados.

Desatacan en su base de atractivos turísticos la riqueza histórica y cultural; plazas, monumentos, museos y zonas históricas; espacios urbanos de recreación y esparcimiento público; la mayoría de los cuales son de bajo valor funcional, estético, y/o conservativo. A pesar de ello, la historia del proceso de formación y desarrollo del turismo en la ciudad ha sido poco coherente, inestable, carente de planificación efectiva, al tiempo que ha sido insuficientemente estudiada y sistematizada, razón por la cual se dificulta el acceso a información científica confiable. 
El sistema actual de turismo está conformado por 26 establecimientos de alojamientos turísticos, -categoría de 3, 4 y 5 estrellas-, razón por la que son los que el Buró de Convenciones y Visitantes de Ciudad Juárez promueve $\mathrm{y}$ recomienda al visitante que acude por información (BCV, 2016). No obstante; según datos reportados por INEGI (2014), se dispone de 163 establecimientos de hospedaje incluyendo categorías inferiores, los cuales ofrecen 8300 habitaciones; pero al mismo tiempo y de manera contradictoria DATATUR (SECTUR, 2015) reporta 4202 unidades totales de habitaciones. Forman además parte del sistema turístico 1260 establecimientos de alimentos y bebidas con categoría turística, en los que se integran restaurantes, cafeterías, discotecas y bares, así como otros centros nocturnos (Secretaría de Economía del Gobierno del Estado, 2016).

En el destino operan agencias de viajes formales e informales, y las estadísticas dependen de los datos que manejan las diferentes entidades. Según la Dirección de Comercio y Turismo del Gobierno del Estado están registradas 29 agencias de viajes; en la Cámara Nacional de Comercio (CANACO) están asentadas 23 agencias de viajes; en tanto la Asociación Mexicana de Agencias de Viajes (AMAV) reporta 10 agencias de viajes, y la Confederación Nacional de Asociaciones de Agencias de Viajes (CONAAV) solo 9 (Valero, En González et al., 2016). Otros establecimientos que forman parte del sistema de turismo corresponden a 20 balnearios, 1 campo de golf, 3 centros principales de convenciones y 3 oficinas de información al visitante, así como 16 empresa arrendadoras de autos, 35 transportadoras turísticas especializadas, 1 aeropuerto, y 4 pasos internacionales (Secretaría de Economía del Gobierno del Estado, 2016).

A nivel local no es posible identificar explícitamente un modelo de desarrollo turístico, ni una consistente proyección sustentable o posicionamiento competitivo del destino con enfoque holístico, por lo que pudiera hablarse de un espacio polivalente, en el que no existe una Organización de Gestión de Destino, a pesar de estar constituidas diversas asociaciones y entidades de gestión, por lo que aún no se ha logrado una adecuada actuación público privada, un verdadero encadenamiento productivo, y una visión sistémica e integrada del destino. Por ende, la gestión se ha basado más en el enfoque empresarial que en el enfoque de destino turístico; se trata de un desarrollo más espontáneo que planificado, carente de bases participativas y con pobre desarrollo endógeno, así como desfavorables niveles de especialización/tematización o una adecuada zonificación turística de todo el espacio, en la que se diferencien roles y funciones turísticas en apoyo al desarrollo integrado.

Con respecto a la categoría de datos turísticos -fundamental para la Gestión del Conocimiento- no existe a nivel local un Observatorio de Turismo, ni están establecidos los estudios de inteligencia turística de mayor 
significación para Ciudad Juárez. La información es dispersa, incongruente, desactualizada y en muchos casos poco accesible. Vale la pena estudiar las experiencias internacionales del Centro de Inteligencia Turística de Madrid (Ayuntamiento de Madrid, 2013) que cruza distintos datos para conocer diversos temas, y de Turespaña (Secretaría de Estado de Turismo, 2016) que dispone de una amplia base de fuentes de información estadística que respalda los intereses turísticos y las "mejores" decisiones.

Hasta el presente no se ha proyectado la conformación de un Destino Turístico Inteligente como concepto avanzado en el turismo, a pesar de acciones aisladas por parte de algunas empresas, que con diferentes niveles de innovación y sustentabilidad han incorporado estrategias orientadas a la atracción y mantenimiento de los flujos de visitantes, pero no con un pensamiento de turismo inteligente asociado a las oportunidades que la ingeniería del conocimiento puede aportar. El turismo como disciplina científica sigue siendo responsabilidad casi exclusiva de las instituciones académicas universitarias y de limitadas instituciones de investigación; en este ámbito, la relación entre el sector empresarial turístico y la academia es extremadamente limitada, sobre todo en términos de resultados relativos a la producción de conocimientos que perfeccionen la gestión empresarial, más allá de las buenas voluntades.

Sistematización del conocimiento aprehendido por los grupos focales con relación al modelo de desarrollo turístico de Ciudad Juárez.

Derivado del análisis de las Ontologías OWL se sistematizaron los conocimientos siguientes. Estos corresponden a cada una de las interrogantes debatidas en los grupos focales, e identificadas como dimensiones resultantes del estudio semántico realizado. Esta información permite caracterizar la percepción de cada grupo focal, evidenciando puntos de encuentros $y$ desencuentros.

\section{Grupo Focal 1-EMPRESARIOS Y TRABAJADORES DE TURISMO (Ver Figura 1).}

Dimensión 1 Vocación e importancia del turismo en la ciudad.

Importancia del turismo local: mejoramiento de la ciudad; generación de empleos; factor de desarrollo económico.

Vocación turística de la ciudad: cultura y deportes.

Dimensión 2 Factores de impacto negativo hasta el presente en la ciudad. 1. Deficiente Gobernanza. Desatención gubernamental y falta de interés por parte del gobierno. Falta de participación ciudadana. Insuficiente coordinación público - privada. Limitadas relaciones inter institucionales. Insuficientes planes de mantenimiento. Problemas de vialidad, falta estacionamiento seguro, y parquímetros. 
2. Inseguridad. Inseguridad y miedo por parte de turistas fronterizos de EEUU. Inseguridad y miedo por parte de empresarios. Recorte de horarios para la vida nocturna a raíz la violencia (en recuperación). Abuso y explotación al visitante.

3. Tramitaciones. Trámites burocráticos para dar apertura a negocios.

4. Medios de Comunicación. Difusión negativa por parte de los medios de comunicación

5. Cultura Turística. Falta de cultura turística. Desconocimiento del perfil del egresado de turismo por parte de los empresarios. Insuficiente capacitación para ofrecer un turismo de alta calidad.

6. Falta de confianza y credibilidad. Pérdida de credibilidad y confianza en el turismo. Falta de unidad y proyección estratégica entre los comerciantes del mismo giro.

7. Falta de Inversión. Falta de valorización de los atractivos de la ciudad. Poca atracción de inversiones. Deterioro de importantes espacios de interés público.

8. Baja calidad de la Oferta Turística. Descuido del turismo receptivo. Insuficiente comercialización de artesanía mexicana. Falta de adecuada atención y calidez al visitante. Limitada estancia de turistas en la ciudad. Inexistencia de productos que permitan prolongar la estancia de turista. Falta de conocimientos con respecto al perfil del visitante de la ciudad.

Dimensión 3 Experiencias desarrolladas hasta el presente en el destino.

1. Voluntad política del sector turístico. Es la primera vez que se ve que la dirección del turismo -funcionarios- se interesan y participan en el debate de este tema.

2. Proyectos comunitarios. Proyecto "Limpiemos la imagen de Cd. Juárez"; Diplomados de guías de turistas; Programa experimental de muestra de arte contemporáneo en hoteles con jóvenes de la universidad (Arte y Arquitectura).

3. Seguridad vehicular. Programa vigilante de vehículos.

Dimensión 4 Estrategias para la consolidación como un destino turístico de experiencias y excelencia a mediano y largo plazo.

1. Imagen y percepción turística. Difusión por parte de universitarios sobre técnicas a utilizar para reforzar el turismo. Mejoramiento de la señalización turística en lugares tales como: aeropuertos, centrales camioneras, puentes internacionales, corredores, zona centro, y carreteras de entradas y salidas a la ciudad. Mayor amabilidad de los oficiales de tránsito hacia los turistas para generar confianza. Mejoramiento de la seguridad pública. Mejoramiento y desarrollo de infraestructura turística. Desarrollo de programas de limpieza y saneamiento urbano. 
2. Planificación estratégica del turismo. Elaboración de directorios de eventos para promoverlos. Plan estratégico para integrar los diversos proyectos deportivos. Diseño de rutas turísticas. Estudio de segmentación del mercado actual y potencial para el desarrollo de productos diversificados y ajustados a la demanda de cada segmento.

3. Cultura en la comunidad. Proyecto artístico cultural para el centro histórico con alumnos universitarios. Programas de capacitación para generar confianza -población local pueda salir a disfrutar de los productos y servicios, a la vez que satisfacer el visitante-. Capacitación a la policía en el idioma inglés para una mejor atención el turismo extranjero.

4. Desarrollo de corredores turísticos. Creación de nuevos corredores. Fortalecimiento de los corredores comerciales y artesanales existentes.

Figura 1 Fragmento de ontología OWL grupo focal de Empresarios

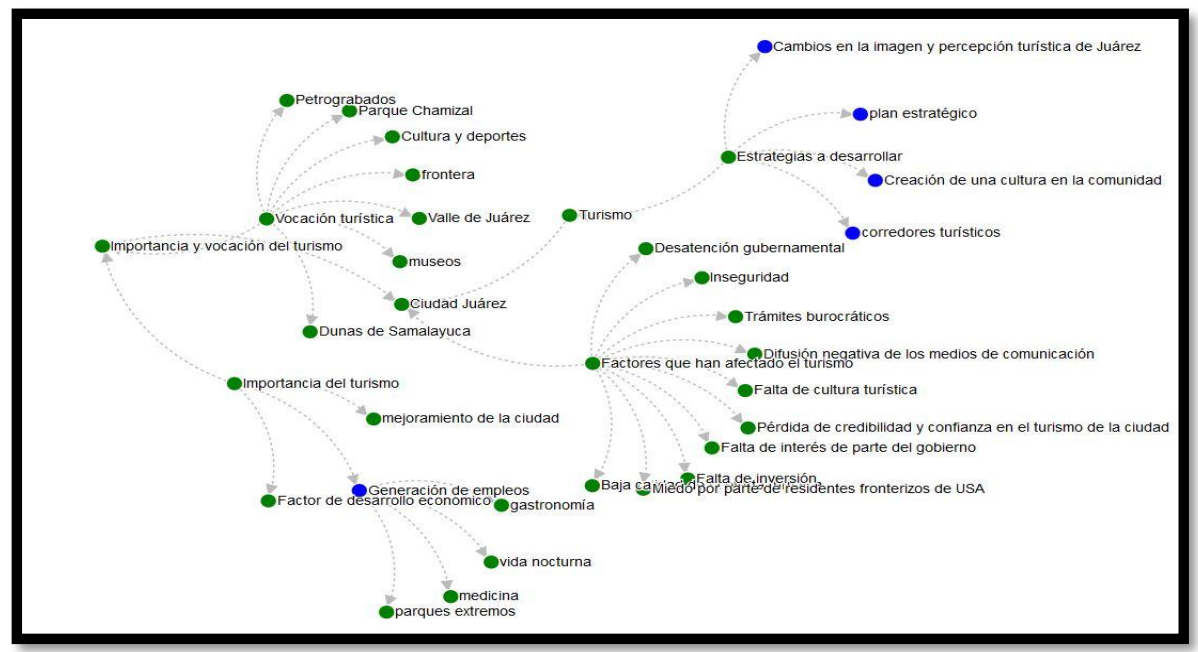

Elaboración: Garay, 2013.

GRUPO FOCAL 2- SECTOR HOTELERO (Ver figura 2).

Dimensión 1 Vocación e importancia del turismo en la ciudad.

Importancia del turismo local: bienestar e intercambio cultural.

Vocación turística de la ciudad: turismo de negocios, nostálgico, de noche, salud, aventuras, deporte extremo, de consulado, de ciudad.

Dimensión 2 Factores de impacto negativo hasta el presente en la ciudad. 1. Falta de Compromiso. Falta de pertenencia y compromiso ciudadano y empresarial. Pérdida de valores y educación en el amor por la ciudad. No sistematicidad en las actividades de planificación, coordinación y control. Falta de cohesión social.

2. Insuficiente difusión. Falta de difusión y trascendencia de los resultados positivos alcanzados. Falta de control de la información que se difunde hacia el exterior. 
3. Patrimonio. Mal cuidado de monumentos, lugar de emplazamiento y su entorno. Pobre mantenimiento a los lugares de interés para el visitante y la ciudad.

4. Inseguridad. Inadecuado trato por parte de los oficiales de tránsito y de federales -turistas no vienen por miedo al atraco-. Inexistencia de un reglamento de turismo con participación de tránsitos y policías. Falta de confianza y reconocimiento social a buenas prácticas de la policía. Altas tasas de incidencias y reportes por robos.

5. Participación. Falta de participación ciudadana en los proyectos turísticos.

6. Atractivos. Insuficiente desarrollo de atractivos. Mala recomendación de la ciudad por parte de residentes. No existencia de una buena guía turística. Pocos centros y puntos de información al visitante e insuficiente rol de los locales. Insuficiente conectividad entre corredores y zonas turísticas respecto a sus aforos. Carencia de espacios para estacionamiento en determinados lugares y tiempos de la ciudad.

7. Eventos. Falta de eventos públicos atractivos en comparación con los privados (feria del tequila, fiesta gastronómica y otros eventos que son privados).

Dimensión 3 Experiencias desarrolladas hasta el presente en el destino. 1. Programa de certificación de parqueros. Profesionalización y calidad del servicio.

2. Eventos de las naciones. Multiculturalidad de la ciudad.

3. Programa Paisano. Atención a visitantes residentes en el extranjero procedentes de EEUU.

4. Programa taxi amigo. Fomento a la comunicación entre los taxistas y los visitantes

5. Corredores turísticos. Experiencia de varios corredores turísticos organizados que comparten y se benefician del trabajo colaborativo, recuperación del espacio, mejora de la convivencia y trabajo con la policía en la prevención, atrayendo comercio y clientes.

Dimensión 4 Estrategias para la consolidación como un destino turístico de experiencias y excelencia a mediano y largo plazo.

1. Cambios en la imagen y percepción turística. Creación de confianza entre todos los actores. Mejoramiento de la percepción local sobre los atractivos. Estimulación a los visitantes que vienen de compras a El Paso para retenerlos en la ciudad. Programas de reforestación y mantenimiento de áreas verdes. Programa de movilidad pública confiable con facilidades para residentes y visitantes. 
2. Desarrollo del clúster turístico de la ciudad. Desarrollo de estudios para la conformación del clúster turístico de la ciudad.

3. Corredores turísticos. Desarrollo de nuevos corredores y consolidación de los actuales atendiendo a su vocación.

4. Plan estratégico de incentivos. Promoción del turismo nocturno como área de oportunidad considerando la zona del Pronaf. Programa de estimulación para el aprovechamiento social de los parques urbanos y espacios públicos. Programa de marketing interno urbano con acciones para proyectar una mejor identidad como destino turístico.

5. Desarrollo de instrumentos de gestión. Programas de comunicación para difundir eventos diversos. Mejoramiento de programas de regulación de comercios y plazas comerciales. Desarrollo de instrumentos de gestión integrada del destino basado en la tipología y características de los corredores y zonas de uso turístico. Programa de certificación de los parqueros.

6. Cultura de la comunidad. Enriquecimiento del comportamiento de la población anfitriona para guiar, ayudar, y atender al visitante. Educación de la cultura ciudadana general sobre la significación del turismo para la frontera. Capacitación al policía de tránsito para la atención al ciudadano y al turista.

Figura 2 Fragmento de ontología OWL grupo focal Sector Hotelero.

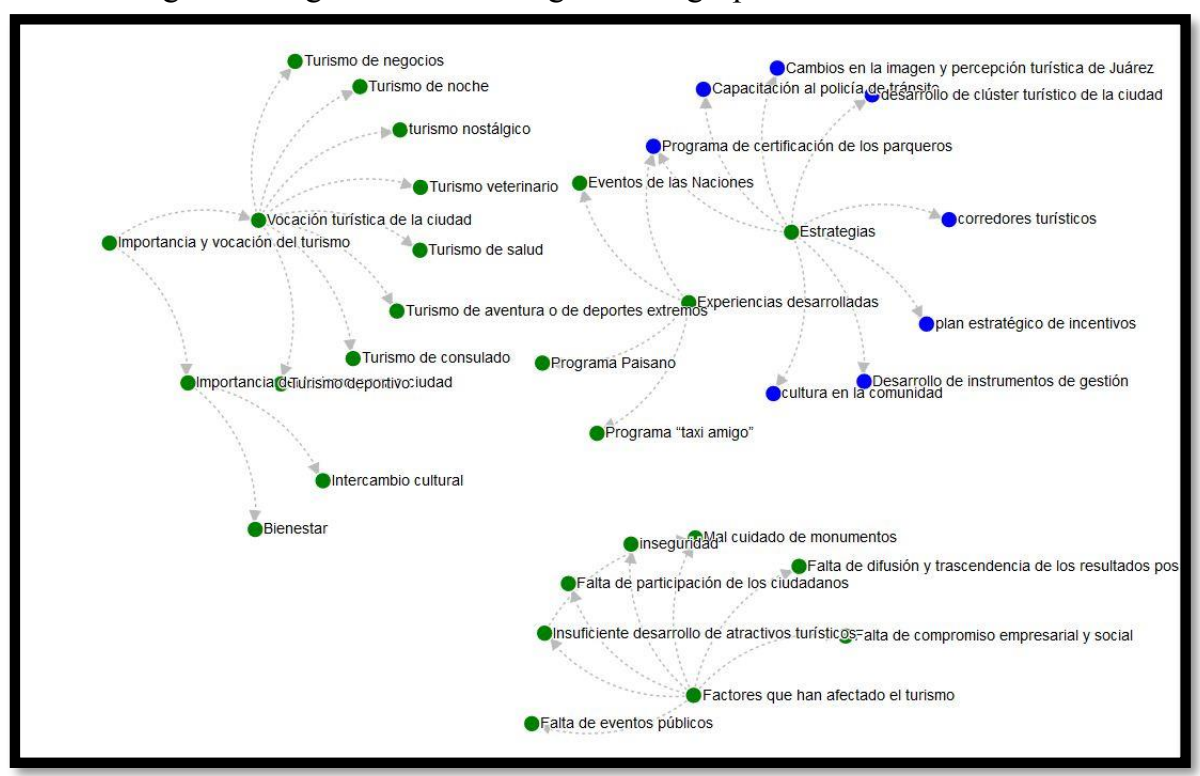

Elaboración: Garay, 2013

GRUPO FOCAL 3 -TOMADORES DE DECISIONES (Ver figura 3). Dimensión 1 Vocación e importancia del turismo en la ciudad.

Importancia del turismo local: económica, recuperación de espacios urbanos. Vocación turística de la ciudad: turismo de negocios, industrial, familiar, consular, de recuerdos, de adultos, de convenciones, de aventura, médico. 
Dimensión 2 Factores de impacto negativo hasta el presente en la ciudad. 1. Insuficinete publicidad turística. No consolidación de segmentos de mercado con valor para la ciudad. Inadecuada publicidad turística (notas rojas...aspectos negativos). Impacto negativo de los medios de comunicación sobre la imagen de la ciudad y falta de seguimiento a las noticias para generar confianza en la gestión. Falta de soporte apropiado para favorecer una buena impresión al llegar a la ciudad.

2. Falta de coordinacion. Falta de coordinación entre los diversos actores locales. Falta de cohesión social e institucional.

3. Falta de recintos para eventos. No se atrean grandes eventos que puedan generar más riqueza y visitantes a la ciudad. No existencia de un parque temático con un producto que pueda dar a conocer la ciudad y que llame la atención del visitante.

4. Turismo informal. Prácticas de turismo informal.

5. Falta de mantenimiento. Mal mantenimiento y cuidado de las áreas verdes ("4 200 zonas verdes de las cuales solo se han limpiado 400"). Mal estado de las vías de comunicación (" $40 \%$ del pavimento a realizar en los siguientes 3 años").

6. Falta de planificacion turística. Cada institución de turismo trabaja para su lado. Falta de conocimientos sobre el presupuesto y recursos federales para programas específicos de turismo. Falta de correspondencia entre una política turística coherente y el presupuesto requerido para su implementación. Falta de focalización sobre el segmento de turismo a que se va a dirigir la ciudad.

7. Inseguridad. Desconfianza e inseguridad ("los centros nocturnos perciben a Seguridad Pública como recaudador"). Miedo a la policía y a tránsito ("extorsión, multas indebidas"). Transmisión de malas experiencias al visitante. Falta de participación ciudadana en la cultura de la legalidad.

Dimensión 3 Experiencias desarrolladas hasta el presente en el destino. 1. Programa Taxi Amigo. Comenzó con 2 grupos, y se quiere abrir un tercero.

2. Creación de corredores turísticos o comerciales. Los corredores comerciales comenzaron con las palabras corredor seguro, pero hay que convertirlos en corredor comercial.

3. Plan estratégico de turismo, Chihuahua. Chihuahua tiene invertido en el turismo ("la inversión ha sido de como 22 millones de pesos").

4. Generación de confianza hacia tránsito y seguridad pública. Ubicación de una leyenda en las patrullas o autos que dice "si manejo mal o abuso repórtame". Unión entre la dirección de tránsito y tráfico para estar mejor comunicados y en colaboración ("con el fin de dar un sentido de orden a la ciudad, delimitar carriles para acabar con la anarquía vial"). 
Dimensión 4 Estrategias para la consolidación como un destino turístico de experiencias y excelencia a mediano y largo plazo.

1. Percepción del destino por visitantes y ciudadanos. Disponibilidad de la información turística de la ciudad en hoteles para facilitarla a visitantes. Programas para el cambio de la percepción ciudadana hacia las estructuras encargadas de la Seguridad Pública y Tránsito. Incorporación de los medios de comunicación masiva a la conformación de la nueva imagen de la ciudad. Estudio para la homologación de la imagen corporativa de los comercios.

2. Capacitación y certificación. Capacitación al personal de policía y tránsito. Capacitación y certificación de taxistas ubicados en puntos de interés turísticos ("él le dice los hoteles, restaurantes-museos- y él le dice cómo anda la violencia en la ciudad").

3. Fomento del talento local. Programas para el fomento del talento local. Activación de tradiciones como las serenatas.

4. Organización de Gestión de Destino. Creación de un Consejo de Turismo Municipal que integre a todos los actores del sistema de turismo local. Creación de una OGD.

5. Regulación y planificación turística. Elaboración participativa de un código de turismo. Estudio de sinergia entre planes, estrategias, proyectos, y otras acciones para lograr una actuación integrada entre todos los actores. Regulación de las tarifas de taxis para reducir el precio actual ("primer contacto y último es con el taxista").

6. Marketing turístico. Segmentación del mercado y elaboración de estrategias especializadas de cobertura. Estrategia de marketing externo para el posicionamiento internacional de la ciudad.

7. Infraestructura. Creación de un parque para niños en miniatura. Mejoramiento del transporte público. Creación de un Centro de Convenciones para atraer eventos mayores.

8. Seguridad. Redimensionamiento de la visión actual de la seguridad hacia un programa de actuación conjunta y de deber ciudadano. Sistema efectivo de control de anomalías provocadas por incidencias que afectan al visitante y verificación de su solución para garantizar la satisfacción de residentes y turistas. Programas eficientes de seguridad pública para que los residentes y visitantes puedan recorrer tranquilamente las calles.

9. Corredores turísticos. Programa para la gestión integrada de los corredores turísticos actuales y en formación, basada en su identidad y vocación ("hay que unirnos, estar en contacto con Seguridad Pública"). 
Figura 3 Fragmento de ontología OWL grupo focal de Tomadores de Decisiones.

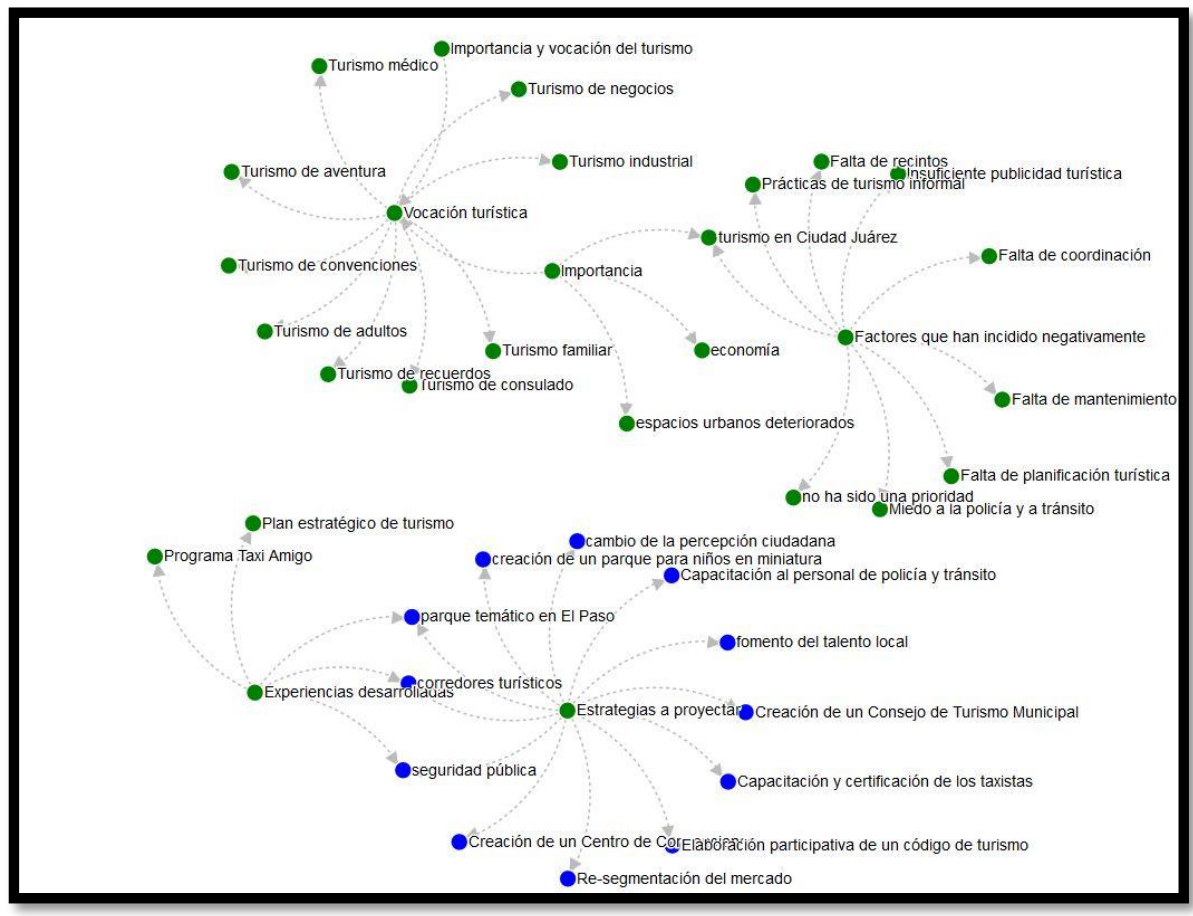

Elaboración: Garay, 2013

GRUPO FOCAL 4 - COMUNIDAD EN GENERAL (Ver figura 4). Dimensión 1 Vocación e importancia del turismo en la ciudad.

Importancia del turismo local: desarrollo económico, crecimiento de otras actividades económicas y sociales, dada su condición de ciudad frontera (servicios médicos a El Paso, Texas, etc.).

Vocación turística de la ciudad: turismo empresarial, de centros nocturnos. Dimensión 2 Factores de impacto negativo hasta el presente en la ciudad. 1. Inseguridad. Miedo e inseguridad que ha impactado negativamente sobre el tejido social de la ciudad ("todos asustados, nadie quiere dar su nombre, muchos transmitimos inseguridad").

2. Falta de confianza y credibilidad. Falta de confianza y credibilidad en tránsito y la policía ("tránsito en la ciudad y la policía causan daño").

3. Déficit de infraestructura. Insuficiente desarrollo de infraestructura en la ciudad. Insuficiencias de los corredores urbanos para paseos peatonales; falta de plazas de estacionamientos en áreas de corredores; inadecuada correspondencia entre la localización de las zonas principales de concentración de hoteles con respecto a restaurantes; insuficiente planificación de los atractivos e incentivos; mal estado de limpieza; falta de proyección estratégica en el turismo; y falta de continuidad de todos los proyectos al producirse cambios de administración. 
4. Limitada inversión. Insuficiente inversión en zonas de desarrollo turístico, problema que relacionan con la falta de innovación y creatividad.

5. Insuficiente cultura. Falta de cultura en Ciudad Juárez ("cultura del servicio se aniquiló"). Falta de vocación y orientación profesional para estudiar y trabajar en el turismo. Pérdida de identidad y de valores ciudadanos. 6. Mala comunicación. Impacto negativo de los medios de comunicación sobre la formación de la imagen de la ciudad.

7. Pobre relación turista anfitrión. Falta de empatía entre residente y visitantes.

8. Pérdida de tradiciones. Pérdida de tradiciones culturales ("la gente no venía a malls, venía a mercados, a oír la música, disfrutar la comida, el mariachi, comprar, etc.").

Dimensión 3 Experiencias desarrolladas hasta el presente en el destino.

1. Crisis de inseguridad vivida. Lecciones de aprendizaje derivadas de la situación de violencia e inseguridad que se vivió ("dentro de lo malo que nos ocurrió años atrás sirvió también para que nosotros nos uniéramos para buscar alternativas como los corredores").

2. Programas implantados en apoyo al turismo. Programa taxi amigo ("bien informado, da sugerencias, se les capacita en historia, primeros auxilios, personalidades que llegaron a la ciudad").

Dimensión 4 Estrategias para la consolidación como un destino turístico de experiencias y excelencia a mediano y largo plazo.

1. Cultura general y especializada. Formación de la cultura de la población local y prestadora de servicios ("amabilidad, calidad del servicio"). Incremento de la información sobre el turismo en la ciudad como base para la valoración y formación de la cultura turística.

2. Política turística. Declaración de una policía turística coherente.

3. Planificación estratégica. Inventario y estudio de la aptitud o vocación turística de cada atractivo atendiendo a su valor funcional de uso turístico, estético, simbólico o representativo, ambiental, y añadidos. Necesidad de una zonificación turística y delimitación de áreas protegidas (“delimitación de espacios urbanos, antros por todos lados"); así como identificación de rutas e itinerarios.

4. Seguridad. Continuidad del programa taxi amigo ("hay que recomendarlo").

5. Inversiones. Programa de atracción de inversiones hacia las maquiladoras de la ciudad.

6. Mercadotecnia. Estudios mercadológicos para identificar los tipos de turismo que necesita la ciudad, y la oferta que debe cubrir la demanda para desarrollar un multiproducto. 
7. Flujos turísticos. Atracción y mantenimiento de los flujos turísticos ("el turista no tiene a donde ir... hay que darle algo para que se quede más tiempo y retenerlo").

8. Medios de comunicación. Reorientación del papel de la prensa ("notas de lo bueno de la ciudad"), incremento de los vínculos del turismo con la prensa local, medios de comunicación extranjeros, y embajadas.

9. Eventos. Elaboración de un calendario de eventos para facilitar información en los hoteles y otros establecimientos turísticos.

Figura 4 Fragmento de ontología OWL grupo focal de Comunidad General.

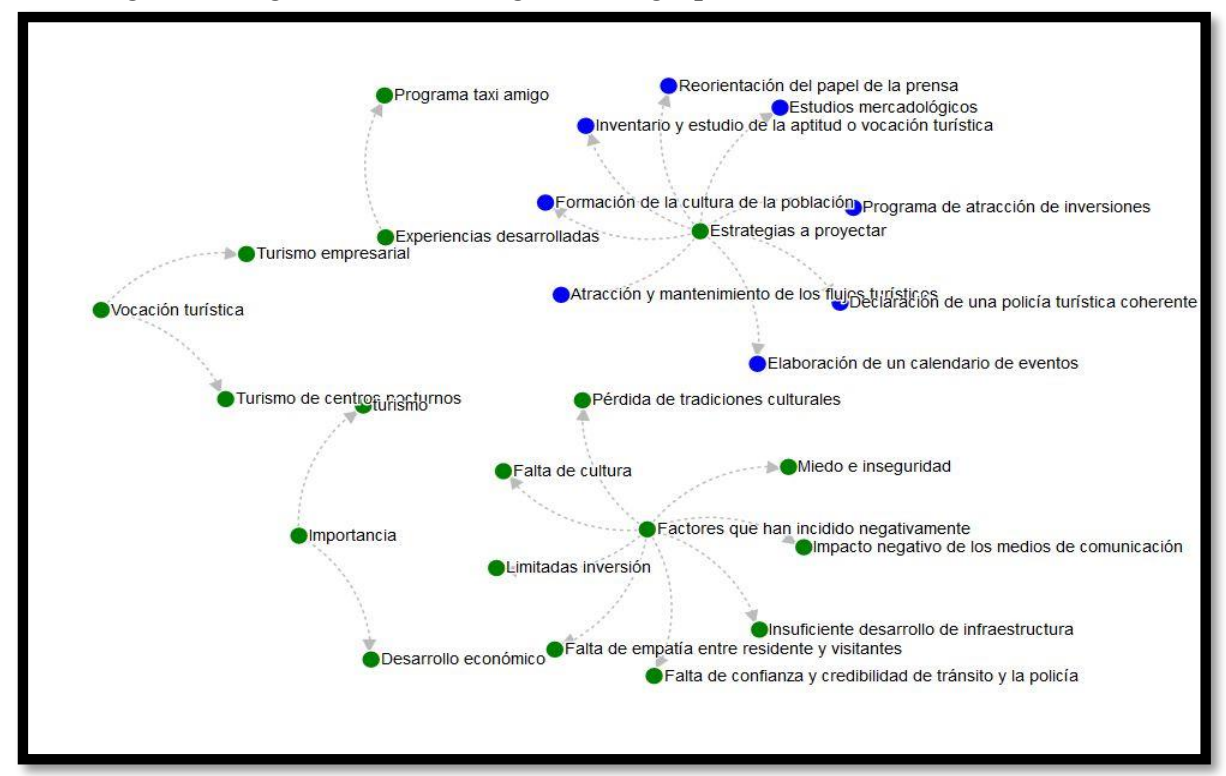

Elaboración: Garay, 2013

\section{Escenario comparado entre las 4 Ontologías OWL correspondientes a cada grupo.}

El análisis comparado del discurso de los grupos focales y las percepciones identificadas permitieron la construcción de un escenario comparado. El análisis parte de la búsqueda de respuestas a la siguiente interrogante ¿Cuáles son los aspectos que más pudieran estar incidiendo en la percepción y proyección del modelo de desarrollo turístico de la ciudad según análisis de las ontologías elaboradas? Obsérvense seguidamente las síntesis presentadas en las tablas y los breves comentarios asociados.

Como se aprecia en la tabla 1, la importancia turística está centrada en la dimensión económica del turismo, solo el grupo 3 (tomadores de decisiones) advierten la recuperación urbana de la ciudad. La vocación turística es relativamente coincidente entre los participantes, a pesar de diferencias entre el rol que deben desempeñar el turismo industrial y cultural. 
Tabla 1. Importancia y vocación del turismo para la ciudad.

\begin{tabular}{|c|c|c|c|c|}
\hline Valoración & Grupo 1 & Grupo 2 & Grupo 3 & Grupo 4 \\
\hline $\begin{array}{l}\text { Importancia } \\
\text { del turismo } \\
\text { local. }\end{array}$ & $\begin{array}{l}\text { Calidad, } \\
\text { empleo, } \\
\text { economía. }\end{array}$ & $\begin{array}{l}\text { Bienestar, e } \\
\text { intercambio } \\
\text { cultural }\end{array}$ & $\begin{array}{l}\text { Económica, } \\
\text { recuperación } \\
\text { de espacios } \\
\text { urbanos. }\end{array}$ & $\begin{array}{l}\text { Económico, } \\
\text { crecimiento } \\
\text { de otras } \\
\text { actividades } \\
\text { económicas y } \\
\text { sociales. }\end{array}$ \\
\hline $\begin{array}{l}\text { Vocación } \\
\text { turística de la } \\
\text { ciudad. }\end{array}$ & $\begin{array}{c}\text { Turismo } \\
\text { cultural, } \\
\text { Urbano, } \\
\text { Cultural, } \\
\text { deportivo, de } \\
\text { frontera, } \\
\text { rural, } \\
\text { patrimonial, } \\
\text { de aventuras. }\end{array}$ & $\begin{array}{l}\text { Turismo de } \\
\text { negocios, } \\
\text { nostálgico, } \\
\text { nocturno, } \\
\text { salud, } \\
\text { aventuras, } \\
\text { deporte } \\
\text { extremo, de } \\
\text { consulado, } \\
\text { de ciudad }\end{array}$ & $\begin{array}{l}\text { Turismo de } \\
\text { negocios, } \\
\text { industrial, } \\
\text { familiar, } \\
\text { consular, de } \\
\text { recuerdos, de } \\
\text { adultos, de } \\
\text { convenciones, } \\
\text { de aventura, } \\
\text { médico. }\end{array}$ & $\begin{array}{c}\text { Turismo } \\
\text { empresarial, } \\
\text { turismo de } \\
\text { centros } \\
\text { nocturnos. }\end{array}$ \\
\hline
\end{tabular}

El reporte de la tabla 2 refleja contradicciones en cuanto a gobernanza, tramitaciones, compromisos, participación, publicidad, coordinación, inversión, y relación turista anfitrión. Coinciden los participantes en puntos tales como inseguridad, confianza y credibilidad, insuficiente comunicación y publicidad, deterioro de infraestructura, y falta de cultura. En general, se valoran bajos los niveles de prioridad del turismo a nivel local, insuficientes niveles de satisfacción de los visitantes (a pesar de las opiniones en línea que también fueron revisadas), insustentabilidad de los atractivos, y baja competitividad empresarial (información no disponible en su totalidad).

Tabla 2. Factores que han incidido negativamente hasta el presente en la ciudad.

\begin{tabular}{|c|c|c|c|c|}
\hline Factores & Grupo 1 & Grupo 2 & Grupo 3 & Grupo 4 \\
\hline $\begin{array}{c}\text { Nivel de } \\
\text { prioridad. } \\
\text { Satisfacción } \\
\text { de turistas/ } \\
\text { visitantes. } \\
\text { Atractivos } \\
\text { turísticos } \\
\text { sustentables. } \\
\text { Empresas } \\
\text { turísticas } \\
\text { competitivas. }\end{array}$ & $\begin{array}{c}\text { Gobernanza. } \\
\text { Inseguridad. } \\
\text { Tramitaciones. } \\
\text { Comunicación. } \\
\text { Cultura } \\
\text { Turística. } \\
\text { Confianza y } \\
\text { credibilidad. } \\
\text { Calidad. }\end{array}$ & $\begin{array}{l}\text { Compromiso. } \\
\text { Difusión. } \\
\text { Patrimonio. } \\
\text { Inseguridad. } \\
\text { Participación. } \\
\text { Atractivos. } \\
\text { Eventos. }\end{array}$ & $\begin{array}{l}\text { Publicidad } \\
\text { turística. } \\
\text { Coordinacion. } \\
\text { Recintos para } \\
\text { eventos. } \\
\text { Turismo } \\
\text { informal. } \\
\text { Mantenimiento } \\
\text { Planificacion } \\
\text { turística. } \\
\text { Inseguridad. }\end{array}$ & $\begin{array}{l}\text { Inseguridad. } \\
\text { Confianza y } \\
\text { credibilidad. } \\
\text { Infraestructura. } \\
\text { Inversión. } \\
\text { Cultura. } \\
\text { Comunicación. } \\
\text { Relación } \\
\text { turista } \\
\text { anfitrión. } \\
\text { Tradiciones. }\end{array}$ \\
\hline
\end{tabular}

En la tabla 3 se advierte pobreza en las estrategias precedentes, lo que puede haber estado relacionado con la crisis de violencia (2008-2011) para la que no hubo preparación, herramientas, ni tiempos para responder de forma proactiva. Se identifican acciones aisladas con diversos niveles de eficiencia y materialización en la práctica del turismo, a pesar de los avances que ya se 
comienzan a percibir por parte de los residentes en la ciudad, pero no aún por parte de los mercados externos.

Tablas 3 y 4. Estrategias para la consolidación como destino turístico de experiencias y excelencia a mediano y largo plazo.

\begin{tabular}{|c|c|c|c|c|}
\hline Estrategias & Grupo 1 & Grupo 2 & Grupo 3 & Grupo 4 \\
\hline $\begin{array}{l}\text { Experiencias } \\
\text { precedentes } \\
\text { desarrolladas }\end{array}$ & $\begin{array}{l}\text { Voluntad } \\
\text { política. } \\
\text { Proyectos } \\
\text { comunitarios. } \\
\text { Seguridad } \\
\text { vehicular. }\end{array}$ & $\begin{array}{l}\text { Certificación } \\
\text { de } \\
\text { parqueros. } \\
\text { Eventos de } \\
\text { naciones. } \\
\text { Programa } \\
\text { Paisano. } \\
\text { Programa } \\
\text { taxi amigo. } \\
\text { Corredores } \\
\text { turísticos. }\end{array}$ & $\begin{array}{l}\text { Programa Taxi } \\
\text { Amigo. } \\
\text { Creación de } \\
\text { corredores. } \\
\text { Plan } \\
\text { estratégico de } \\
\text { turismo. } \\
\text { Confianza } \\
\text { hacia } \\
\text { seguridad. }\end{array}$ & $\begin{array}{c}\text { Crisis de } \\
\text { inseguridad } \\
\text { vivida. } \\
\text { Programas } \\
\text { implantados en } \\
\text { apoyo al } \\
\text { turismo. }\end{array}$ \\
\hline $\begin{array}{l}\text { Estrategias a } \\
\text { proyectar }\end{array}$ & $\begin{array}{l}\text { Imagen y } \\
\text { Percepción } \\
\text { turística. } \\
\text { Planificación } \\
\text { estratégico. } \\
\text { Cultura. } \\
\text { Corredores } \\
\text { turísticos. }\end{array}$ & $\begin{array}{l}\text { Imagen y } \\
\text { percepción. } \\
\text { Clúster } \\
\text { turístico. } \\
\text { Corredores. } \\
\text { Incentivos. } \\
\text { Gestión. } \\
\text { Cultura. }\end{array}$ & $\begin{array}{c}\text { Percepción del } \\
\text { destino. } \\
\text { Capacitación y } \\
\text { certificación. } \\
\text { Talento local. } \\
\text { OGD. } \\
\text { Regulación y } \\
\text { planificación. } \\
\text { Marketing } \\
\text { Infraestructura. } \\
\text { Seguridad. } \\
\text { Corredores. }\end{array}$ & $\begin{array}{c}\text { Cultura. } \\
\text { Política } \\
\text { turística. } \\
\text { Planificación } \\
\text { estratégica. } \\
\text { Seguridad. } \\
\text { Inversiones. } \\
\text { Mercadotecnia. } \\
\text { Flujos } \\
\text { turísticos. } \\
\text { Comunicación. } \\
\text { Eventos. }\end{array}$ \\
\hline
\end{tabular}

Continuando el análisis en la tabla 4, el grupo de empresarios enfatiza mucho en la imagen y percepción turística, hecho que es advertido por el resto de los grupos, aunque el grupo de comunidad no lo declara explícitamente. La cultura de la comunidad anfitriona es percibida por todos los grupos como aspecto a priorizar, así como puntos relacionados con la planificación turística, el marketing interno y externo. Los grupos de empresarios y del sector hotelero tienen percepciones diferenciadas respecto a los tomadores de decisiones sobre la problemática en cuanto a enfoques; la comunidad en su condición de anfitriona del turismo enfatiza la seguridad, la comunicación de la ciudad por todos los medios, y la falta de actividades y eventos que afectan a los propios residentes.

La integración de todas las percepciones permite generar el siguiente conocimiento colaborativo con respecto al modelo de turismo percibido por los grupos focales participantes en Ciudad Juárez (Figura 5). Tales constructos y su desarrollo ulterior pueden servir como punto de partida para la elaboración y operacionalización del Plan Estratégico de Desarrollo Turístico de este importante destino fronterizo. 
- Vocación turística: Turismo de consulado, industrial, nocturno, familiar, salud, aventuras, gastronómico, deportivo, fronterizo, negocios, y eventos.

- Problemas percibidos: atractivos turísticos, entorno urbano; seguridad y bienestar; planta turística; servicios e infraestructura; gestión público privada; atracción y retención de visitantes; información turística; educación y cultura;

- Ámbitos estratégicos para la sustentabilidad: institucional y legislativo; territorial ambiental; económico mercadológico; sociocultural; y tecnológico.

- Estrategias a proyectar: desarrollo de productos turísticos; señalización turística; limpieza y saneamiento urbano; planificación y organización turística; marketing urbano; programas de reactivación turística; sistema de turismo responsable y seguro; seguridad pública y turística.

Figura 5 Fragmento de ontología OWL correspondiente al total de todos los grupos focales.

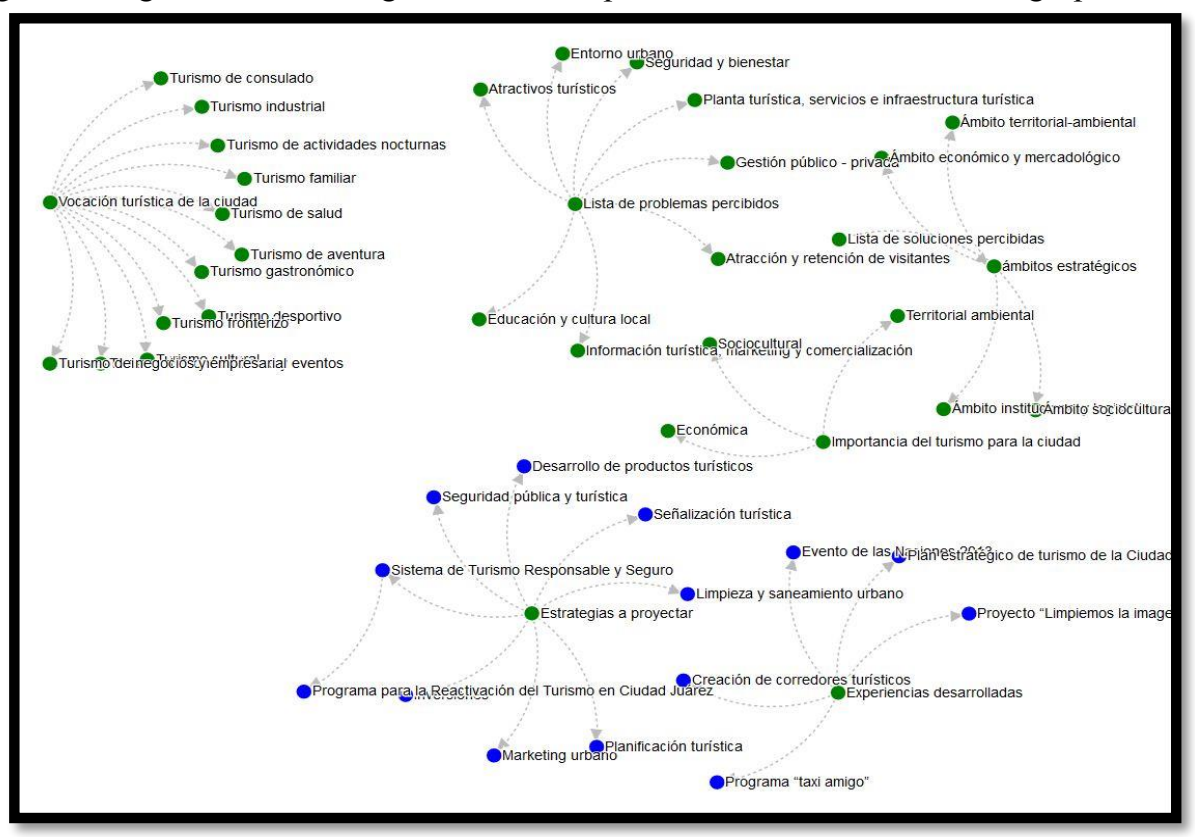

Elaboración: Garay, 2013.

\section{Conclusiones}

La Ingeniería del Conocimiento aplicada a los estudios de percepción del modelo turístico de Ciudad Juárez, utilizando Ontologías OWL derivadas del Léxico Extendido del Conocimiento de este Dominio, es un objeto de estudio novedoso que demuestra ser una valiosa herramienta para facilitar el análisis y comprensión de los conocimiento empíricos y teóricos de que son portadores los diferentes actores involucrados a nivel de destino con el desarrollo del turismo sustentable. Refuerza y posiciona el beneficio de la 
investigación basada en el enfoque interdisciplinar como alternativa viable para la integración de aplicaciones diversas al estudio de objetos, fenómenos y procesos turísticos vinculados con la economía, la sociedad y el medio ambiente.

La sistematización y estudio de las experiencias relacionadas con el análisis del turismo como disciplina científica y la contribución de la Ingeniería del Conocimiento y el turismo inteligente al conocimiento de la percepción de los impactos del turismo abre una nueva oportunidad que pudiera enriquecer la formación de una teoría referente al conocimiento turístico en lo relativo a su plataforma conceptual, basada en las aportaciones de los actores involucrados. Este enfoque puede ser de gran utilidad en la investigación científica de diversos problemas del turismo que requieren de la participación e integración de las comunidades locales.

Como parte de la validación de las Ontologías OWL generadas y su visualización se comprobó que al experto en turismo -a pesar de no estar familiarizado con el concepto de ontologías- le puede resultar fácil la interacción con la herramienta para generar y visualizar los modelos de los diferentes dominios del conocimiento objeto de estudio. La visualización de las ontologías permitió entender fácilmente el resultado obtenido, al tiempo que permitió una visualización que ayudó a obtener una perspectiva más amplia del dominio en cuanto a conceptos y relaciones. Resultó de gran provecho la visualización de las relaciones que se generaron con las ontologías, lo cual valida su posible factibilidad de uso en los estudios del turismo, a la vez que da oportunidad para el perfeccionamiento ulterior y corroboración práctica.

KDEL + OWL permitió detectar un número importante de conceptos de interés para la comprensión de las percepciones de los participantes, lo que facilitó la conformación de una base de opiniones, la cual puede servir de guía a los procesos de toma de decisiones en lo relativo al Programa de Reactivación Turística en Ciudad Juárez. El análisis manual, o el uso de otras aplicaciones más básicas no habrían permitido la claridad y comprensión de los resultados.

El establecimiento de las relaciones entre los conceptos visualizados mediante la generación de los modelos conceptuales OWL permitió analizar y entender las perspectivas y necesidades de Ciudad Juárez con respecto al desarrollo del turismo sustentable. Aportaron valiosa información las relaciones que se visualizaron en cada modelo con respecto a la importancia y vocación turística de la ciudad, los factores de impacto negativo advertidos hasta el presente, las experiencias precedentes valoradas como lecciones de aprendizaje, y las nuevas estrategias de desarrollo turístico que deben ser proyectadas. Tales resultados permitirían afirmar para el caso de estudio que 
el conocimiento científico es realmente un "valor agregado" para la gestión del turismo sustentable.

\section{References:}

Abril, Gonzalo. 1997. Teoría general de la información datos, relatos y ritos. Cátedra. Madrid.

Aramberri, Julio. 1988. El paraíso... ¿perdido? Sobre algunas teorías del turismo, Madrid, Instituto Español de Turismo. España.

Ayuntamiento de Madrid. 2013. Así funciona el Centro de Inteligencia Turística de Madrid. Jueves 25 de abril de 2013. http://www.espormadrid.es/2013/04/asi-funciona-el-centro-de-

inteligencia.html [Recuperado en 14 de junio de 2016].

Buró de Convenciones y Visitantes de Ciudad Juárez /BCV/. 2016. Directorio de empresas hoteleras recomendadas. Documento de trabajo. Marzo del 2016. (Inédito).

Cabrini, Luigi. 2014. Tendencias del turismo sostenible y el rol del Consejo Global (GSTC). Presidente de la Junta Directiva del Consejo Global de Turismo Sostenible (GSTC) y Consejero del Secretario General, Organización Mundial del Turismo (OMT). Primer Congreso de Eficiencia Energética y Sostenibilidad en el Sector Turístico. Palma de Mallorca, España. http://docplayer.es/2312294-Tendencias-del-turismo-sostenible-y-el-rol-delconsejo-global-gstc.html [Recuperado el 02 de junio de 2016].

Castillo Nechar, Marcelino. 2011. Epistemología critica del turismo ¿qué es eso? Turismo Em Análise. Vol. 22. No. 3, p. 516 - 538. Diciembre de 2011.

Castro Hernández, Sarahí. 2016. Estrategias de Innovación del Marketing Digital para las Agencias de Viajes en Ciudad Juárez. Informe de Investigación Requerido para la Obtención del Título de Licenciado en Turismo. Asesor. Dr. Manuel Ramón González Herrera. Universidad Autónoma de Ciudad Juárez. México (inédito).

Garay Santos, Yanet del Carmen. 2013. Generación semi-automática de una ontología OWL derivada de un Léxico Extendido del Conocimiento del Dominio (KDEL). Reporte Técnico de Investigación. Junio de 2013. Requisito para la obtención del título de Ingeniero en Sistemas Computacionales. Asesorada por la Dra. Karla Olmos y el Dr. Jorge Rodas. Instituto de Ingeniería y Tecnología Departamento de Ingeniería Eléctrica y Computación. Universidad Autónoma de Ciudad Juárez. (Inédita).

Gil, G. D. 2002. Herramienta para implementar LEL y escenarios (TILS). Doctoral Dissertation. Facultad de Informática.

Goel, S. 2012. Transformation from LEL to UML. International Journal of Computer Applications, 48.

González Herrera, M. 2010. Manual de turismo para agentes emprendedores de negocios en Pymes. Editorial CEP. Madrid. España. 
González Herrera, Manuel y Ana Valero Quezada. 2016. Empresas de servicios de viajes turísticos: de la dimensión teórica a la actividad práctica. Editorial Trillas (proceso editorial).

Gruber, T. R. 1993. A translation approach to portable ontology specifications. Knowledge acquisition, 5(2), 199-220.

Guevara Ramos, Rosana (coordinadora). 2006. Estudios multidisciplinarios en turismo. Volumen 1, 2006. Secretaría de Turismo Centro de Estudios Superiores en Turismo. Red de Investigadores y Centros de Investigación en Turismo. SECTUR. México.

Hossian, A. 2012. Modelo de proceso de conceptualización de requisitos (Doctoral Dissertation. Facultad de Informática.

Instituto Nacional de Estadística y Geografía /INEGI/. 2014. Anuario Estadístico y geográfico de Chihuahua. INEGI. México.

Instituto Profesional de Chile. 2016. Ingeniería en Gestión Turística. Brochure 2016. http://www.ipchile.cl/carreras/ingenieria-en-gestion-turistica/ [Recuperado el 15 de junio de 2016].

Lock, R., Dobson, G., \& Sommerville, I. 2005. Addressing the contract issue, standardization for QoS.

López De Ávila Muñoz, Antonio y Susana García Sánchez. 2015. Destinos Turísticos Inteligentes. http://www.minetur.gob.es/Publicaciones/Publicacionesperiodicas/Economia Industrial/RevistaEconomiaIndustrial/395/LOPEZ\%20DE\%20AVILA\%20y \%20GARCIA.pdf

Loucopoulos, P., \& Zicari, R. 1992. Conceptual modeling, databases and CASE: an integrated view of information systems development. John Wiley $\&$ Sons, Inc.

Morín, E. 2010. Sobre la interdisciplinariedad. Publicaciones Universidad ICESI. Cali. Colombia. Publicado en el Boletín No. 2 del Centre International de Recherches et Etudes Transdisciplinaires (CIRET). París.

Oberg, R., Probasco, L., Ericsson, M. 1998. Applying Requirements Management with Use Cases. Rational Software Corporation.

Olmos K. y J. Rodas, 2014. KMoS-RE: knowledge management on a strategy to requirements engineering. Journal Requirements Engineering. Volume 19, Issue 4, November 2014. Pages 421-440. USA.

Palma, J. T.; E. Paniagua, F. Martín y R. Marín. 2000. Ingeniería del Conocimiento. De la Extracción al Modelado de Conocimiento. Inteligencia Artificial. Revista Iberoamericana de Inteligencia Artificial. No.11 (2000), pp. 46-72. AEPIA http://aepia.dsic.upv.es/ [Recuperado el 20 de junio de 2016]. Popper, Karl. R.; y Víctor Sánchez de Zavala. 2008. La lógica de la investigación científica. $2^{\mathrm{a}}$ edición. Tecnos. España. 
ROTACODE. 2014. Un concepto avanzado de Turismo, el Turismo Inteligente. Junio $30,2014$. https://rotacode.wordpress.com/2014/06/30/un-concepto-avanzado-deturismo-el-turismo-inteligente/ [Recuperado el 14 de junio de 2014]. Sampaio do Prado Leite, J. C., \& Franco, A. P. 1993. A strategy for conceptual model acquisition. In Requirements Engineering, 1993. Proceedings of IEEE International Symposium on (pp. 243-246). IEEE.

Sandoval Medina, Eric Omar. 2015. Sistema localizador de especialistas basado en técnicas de gestión y representación del conocimiento en el dominio de crisis de turismo. Requisito para la obtención del título de Ingeniero en Sistemas Computacionales. Asesora Dra. Karla Olmos Sánchez. Departamento de Ingeniería Eléctrica y Computación. Instituto de Ingeniería y Tecnología. UACJ. (Inédito).

Schreiber, G. (Ed.). 2000. Knowledge engineering and management: the CommonKADS methodology. The MIT Press.

Secretaría de Economía del Gobierno del Estado, Dirección de Turismo, Departamento de Gestión. Establecimientos de alimentos y bebidas de Ciudad Juárez. Comunicación personal.

Secretaría de Estado de Turismo. 2016. Turespaña. Gobierno de España. http://www.tourspain.es/es-es/Paginas/index.aspx [Recuperado en 14 de junio de 2016].

Secretaría de Turismo /SECTUR/. 2015. Estadísticas más recientes de la actividad del sector turismo. http://www.datatur.sectur.gob.mx/EV_Tarjetas/Cuadernillo_2015_Semana_0 3.pdf [Recuperado el 01 de junio de 2015].

SEGITUR. s/a. Destinos Turísticos Inteligentes. SEGITUR, Turismo e Innovación. Presentación. España. http://www.segittur.es/opencms/export/sites/segitur/.content/galerias/descarg as/documentos/Presentacin-Destinos-Tursticos-Inteligentes.pdf [Recuperado el 23 de junio de 2016].

Sidhu, A. S., Dillon, T. S., \& Chang, E. 2006. Integration of protein data sources through PO. In Database and Expert Systems Applications (pp. 519527). Springer Berlin Heidelberg.

Velázquez Oropesa, Dolores. 2013. La importancia de la reingeniería en la actividad turística. Universidad Autónoma del Estado de México. RI UAEM EX. https://ri.uaemex.mx/handle/20.500.11799/40403 [Recuperado el 13 de junio de 2016]. 